\title{
Firmado con un klínex de Élmer Mendoza
}

México, Tusquets, 2009.

ISBN 9786074211092

Pablo Brescia

University of South Florida. Estados Unidos. pbrescia@cas.usf.edu

$\mathrm{V}$ eloces, lúdicos, obsesivos. Pero no: ligeros, banales, enfermos. Los textos de este libro podrían caracterizarse con la adjetivación tripartita que parece ser la marca de estilo del narrador sinaloense. Mendoza saca a la luz Firmado con un klínex, un libro de cuentos, después de varias novelas exitosas. Y sabe que el cuento es un animal diferente. El escritor dominicano Juan Bosch lo llamaba "el tigre de la fauna literaria" porque no puede sobrarle ni un gramo de carne: debe ser todo músculo, tenso para el ataque. Mendoza ha decidido hacer de Firmado con un klinex un laboratorio donde experimentar con diversas formas y temas, dialogando, subvirtiendo, componiendo y recomponiendo lo literario. Buen perceptor de su oficio, adopta una actitud cortazariana de destruir para construir. Esta "irreverencia reverente" circula por las tres áreas principales del libro.

En la primera, los trece cuentos de Firmado con un klinex, dispares en su temática y en sus registros, dejan entrever una visión de mundo plasmada en un estilo distintivo. Como se dijo: veloz, pero no ligero. Las frases de Mendoza son cortas, rápidas, henchidas de significados que el lector debe activar. Para presentar a los personajes de "Rompecabezas", elige comenzar el relato así: "Arquitectos" (13). La adjetivación tripartita a la que hacíamos referencia en el comienzo aparece en varios relatos. El capitán Guarniz de "Firmado con un klínex" se describe como "un hombre canoso, alto, pasado de peso" (26); en "Postal para Diego Luna", la descripción de la MUjer es ésta: "Rostro sosegado, serio, camina con parsimonia" (48); en "Regalo de cumpleaños (Gran desierto de Altar, Sonora, México)", el guardia que habla con la pareja aventurera se identifica como "moreno claro, baja estatura, mirada lánguida" (69). Este fraseo tiene que ver, claro está, con el ritmo. La narración es rápida, pero también se elabora con oraciones que nos des- 
cubren una voz diferente; por ejemplo, cuando se hace la presentación de Adán Puskas, el personaje principal de "La casa de las sirenas", se dice: "Su magro equipaje indicaba que no se quedaría mucho y un aire de desconcierto permitía intuir en su rostro duras batallas por resolver" (57). A este estilo plasmado en lenguaje se le agrega el intento de captación de la oralidad, no tanto en términos de un área geográfica en particular -aunque muchos personajes son notablemente norteños- sino más bien en la ruptura de ciertas normas establecidas tradicionalmente para contar una historia. Por ejemplo, véase el intercambio en "Si te vas a enamorar de alguien que sea asi", donde lo que hay son, sobre todo, voces, ecos cruzados: "No quiero ser tu chica o lo que estés pensando, y mis ojos no cuentan: malditos traidores, me meten en cada aprieto, mordí la hamburguesa. Me encanta que lo digas, mascullé con la boca llena, sonrió" (22).

La segunda área de esta irreverencia reverente tiene que ver con la experimentación con las diversas formas que puede adquirir un cuento. Hay dos grupos de textos en este libro. Uno está integrado por los relatos que expresan una narratividad basada en la acción: "Firmado con un klínex", "La casa de las sirenas", "La secta de Gutenberg" y "La decisión" se inclinan hacia esa tendencia y, no por casualidad, son los más largos. En el otro grupo, los cuentos buscan su narratividad de otras maneras, por ejemplo con las técnicas cinematográficas que se hacen explícitas en las palabras "Exit", "Disolvencias" y "Flashback" de "Postal para Diego Luna", con la minificción ecológica de "Plop" y también con un recurso que destaca en la respiración de casi todos los relatos de este grupo: el comienzo in medias res que "dialoga" la historia, haciendo añicos la autoridad del narrador. Está en, por ejemplo, "Cuerpo", que comienza: "Soy miss Sinaloa, dijo miss Sinaloa tocándose el pelo. Soy Yo, expresó Yo bastante inquieto, ¿gustas una cerveza? ¿Una cerveza? Qué tacaño, creí que ibas a invitarme una cervecería” (43). Y también está en la alternancia de perspectivas de "Ytsé", raro cuento de ciencia ficción. Una de los mejores narraciones de la colección combina eficazmente ambos grupos. Es "Regalo de cumpleaños (Gran desierto de Altar, Sonora, México)", donde se narra el socorrido tópico del intento de salirse de la rutina de la pareja mediante el emplazamiento de un ritual turístico de un humor tenso y cruel. Como se dijo: lúdico, pero no banal.

La irreverencia reverente también aparece en la siguiente área de este libro: la relación con la literatura. Lejos de la intertextualidad enjundiosa o gratuita, los personajes de Mendoza son literarios casi a su pesar: las letras, la lectura, los escritores, aparecen en situaciones insospechadas. En el cuento que da título al libro, el detective, el zurdo Mendieta, querido personaje del 
escritor sinaloense, investiga suicidios masivos de mujeres: "Cinco como Virginia Wolf, doce a la Hemingway, seis a la Pizarnik" (27). Inmediatamente después de estas cultas referencias, vuelta a la acción y a la oralidad: "¿Gusta desayunar" (27). No develamos el final de esta buena trama que incluye una femme fatale, una piromaníaca, disparos y huidas y una telenovela futurista que pregona peligrosamente la felicidad. La literatura aparece hasta en el fútbol cuando, en "Gard", Mendoza imagina un encuentro entre alter egos del francés Zinedine Zidane y el italiano Marco Materazzi y uno de ellos pregunta: "¿Sabes quién es Albert Camus"? El final de esta ficción es la realidad del famoso cabezazo del mundial del 2006. Para Mendoza, la literatura está en la vida y entonces se arma un cuento - "Fiesta" - con frases y situaciones desopilantes de Arturo Pérez Reverte, Daniel Sada, Eduardo Antonio Parra, Cristina Rivera Garza, Alvaro Enrigue, Hernán Lara Zavala, Rosa Beltrán y Mario Bellatín, entre otros. Y también aparece un relato muy divertido, "La secta de Gutenberg", donde una pareja contrata a un viejo asesino para que asista al sexto congreso mundial de no-lectores y mate al cabecilla de la organización. La relación con la literatura se resume en este momento de "La decisión", cuando dialogan los dos personajes principales: “¿Usted qué hace?, si se puede saber. Voy a la universidad. Estudio literatura. No parece. ¿No? Nunca he podido tratar con estudiantes, siempre que me compran yerba tratan de chingarme, quieren de la especial y pagar por la más barata. Hay de todo" (101). ¿Obsesivo? Sí. ¿Enfermo? No.

Está bien que Firmado con un klínex abra con "Rompecabezas" y cierre con "La decisión". Porque el lector que entre a este libro deberá decidir el armado de esta miscelánea colección. En ese primer cuento de una pareja que recuerda y busca y se las rebusca para ver cómo seguir, tópico conocido si los hay, Mendoza desrealiza la situación y le pone Tierra y Fuego a sus personajes principales y Aire y Agua a otros dos que van a causar un in crescendo propio de los relatos memorables. Y la tensión del último relato se propone en el contrapunteo entre un hombre que silba el himno, siembra cannabis $y$, repentinamente, se encuentra una olla que -cree-contiene riquezas y el estudiante de literatura que se ha robado a la hija del capitán de policía. ¿Dónde está el conflicto? El viejo, que ha salvado al estudiante de morir ahogado, quiere regalarle la olla y el joven no quiere aceptarla. Reverencia ante la estructura, irreverencia en el lenguaje y en la discursividad, en el que es el mejor relato del libro. 